Available online at www.jmle.org

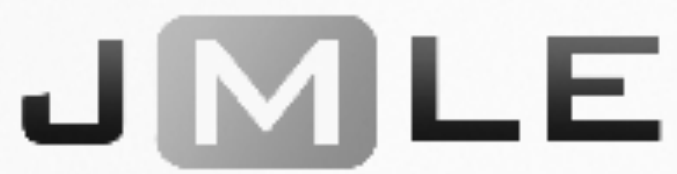

The National Association for Media Literacy Education's

Journal of Media Literacy Education 10 (2), 11 - 32

\title{
Media Literacy and Climate Change in a Post-Truth Society
}

\author{
James S. Damico \\ Indiana University \\ Mark Baildon \\ National Institute for Education, Singapore \\ Alexandra Panos \\ University of Nebraska at Omaha
}

\begin{abstract}
In this article we draw from ecolingusitics and a civic media literacy framework to consider what happened when three pairs of preservice teachers with different academic backgrounds and climate change beliefs jointly evaluated the reliability of two media sources that make opposing arguments about climate change. An ecolinguistics perspective attends to the environmental impact of the "stories-we-live-by" and a civic media literacy lens highlights the centrality of dialogue and deliberation along with critical reading when evaluating the reliability of information sources about complex socioscientific topics like climate change. Our findings highlight the ways the three pairs of preservice teachers considered three aspects of reliability: provenance, purpose, and content. Findings also point to three reliability stories that the preservice teachers drew on as they evaluated the two media sources: (1) having the "other side" represented, (2) wanting more information or evidence to support an argument, and (3) acknowledging one's own identity and perspectives.
\end{abstract}

Keywords: media literacy, climate change, reliability

Stephen Colbert, late night show satirist, coined the neologism "truthiness" back in 2005, which The Oxford Dictionary defines as: "the quality of seeming or being felt to be true, even if not necessarily true." Colbert used the term to account for the ways President George W. Bush explained his "from the gut" approach to decision-making i.e., if something "felt" true it was true. The 2016 U.S. presidential campaign and the election of Donald Trump witnessed other terms gaining prominence in our national lexicon, including "fake news" and "post-truth," the latter earned Word of the Year honors in 2016 from the Oxford Dictionary, which defined "post-truth" as "relating to or 
denoting circumstances in which objective facts are less influential in shaping public opinion than appeals to emotion and personal belief."

The issue of climate change exemplifies the ways people in the U.S. are living in a "post-truth" society. Despite the consensus among climate change scientists that the planet is heating up and humans are a primary cause of this warming, many people continue to disagree with or deny the science. President Donald Trump, like many Republican lawmakers in the U.S. Congress, represents this position with his dismissive stance toward climate change, calling it a "hoax." The first head of the Environmental Protection Agency (EPA) under the Trump administration, Scott Pruitt, has also denied human-caused climate change and has championed severe budget cuts to climate change-related programs.

In this article we draw from ecolingusitics (Stibbe, 2015) and a civic media literacy framework (Damico, Panos \& Baildon, 2018; Masyada \& Washington, 2016) to consider what happened when three pairs of preservice teachers with different academic backgrounds and climate change beliefs jointly evaluated the reliability of two media sources that make opposing arguments about climate change. An ecolinguistics perspective attends to the environmental impact of the "stories-we-live-by" (Stibbe, 2015) and a civic media literacy lens highlights the centrality of dialogue and deliberation along with critical reading when evaluating the reliability of information sources about complex socioscientific topics like climate change.

Our findings highlight the ways the three pairs of preservice teachers considered three aspects of reliability: provenance, purpose, and content. Findings also point to three reliability stories that the pre-service teachers drew on as they evaluated the media sources: (1) wanting the "other side" represented, (2) wanting more information or evidence to support an argument, and (3) reasoning through one's own identity and perspectives. Reliability stories, as we define them here, are a particular set of what Stibbe (2015) calls "stories-we-live-by" which merit careful scrutiny because these are "not immediately recognisable as stories" (p. 5). For example, while these three reliability stories appear to be useful to determine source reliability, each is a potential cause for concern. Making sure we have balance with "the other side" represented is not useful if the other side is based on false or inaccurate information. Similarly, the acquisition of more information to support an argument is not worthwhile if the information is faulty or untrue. Moreover, in our information-rich world, it is easy to locate additional information to support just about any perspective or argument. Finally, it is not enough for readers to acknowledge their backgrounds and perspectives (e.g., art, social studies, math, or science education; politically conservative or liberal). Readers (all of us) need to vigilantly examine their biases, beliefs, values, and ideas to become more aware of how these shape and often limit understanding.

\section{LITERATURE REVIEW}

The importance of discerning the reliability of sources is not new, yet the expansion of new information and communication technologies has been remaking the ways we read, write, and communicate, leading to "new literacies" in a $21^{\text {st }}$ century world (Lankshear \& Knobel, 2003; Leu, Kinzer, Coiro, \& Cammack, 2004; Liu, 2005). Media literacy education can assist students in making clearer distinctions between 
misinformation and evidence-based information online Kahne \& Bowyer, 2017), yet the Internet poses particular challenges, as it produces inexhaustible streams of information sources with many not vetted through traditionally trusted channels (Burbules, 2001). One result is the increased likelihood that online readers will absorb information that conforms to their own perspectives (Jamieson, 2008; Prior, 2013; Kahne \& Bowyer, $2017)$ with greater odds they live in media bubbles or information "echo chambers" (Jamieson \& Cappella, 2008; Manjoo, 2008).

It likely comes as no surprise, then, that people's knowledge and their ability to analyze information about divisive political topics can be limited (Kahne \& Bowyer, 2017; Lavine, Johnston, \& Steenbergen, 2012; Taber \& Lodge, 2006). People's different political preferences and affiliations can lead to distinct beliefs and convictions about essential facts when it comes to divisive subjects like income inequality (Bartels, 2009), the Iraq War (Kull, Ramsay, and Lewis, 2003), and climate change (McCright \& Dunlap, 2011) where there can even be a "boomerang effect" as people draw conclusions about sources that only align with their climate change beliefs (Hart \& Nisbet, 2011). Youth and young adults can struggle with evaluating online truth claims about controversial issues (Kahne \& Bowyer, 2017) and recognizing misleading information online (Wineburg, McGrew, Breakstone, \& Ortega, 2016). In a recent large-scale study, researchers found that middle school, high school, and college students had difficulty determining who was behind information that was presented, assessing evidence, and scrutinizing other sources (McGrew, Ortega, Breakstone, \& Wineburg, 2017; Wineburg, et al, 2016).

Recent studies have also demonstrated the power of fake news and misinformation to overwhelm accurate or verifiable information in social media due to its novelty and its ability to arouse strong emotions (Vosoughi, Roy, \& Aral, 2018). Combined with the increasing lack of trust in formerly respected sources of information, such as scientific expertise, academia, and traditional media, and the spread of online social networks that reinforce selective exposure to views and information that confirms pre-existing beliefs while reducing tolerance for alternative viewpoints and new information, fake news spreads faster, more broadly, and with greater impact than verifiable information (Kavanagh \& Rich, 2018; Manjoo, 2008; Vosoughi, et al, 2018).

A study by the Rand Corporation (Kavanagh \& Rich, 2018) also identifies several trends that have affected political and civil discourse around public policy issues, such as climate change. For example, there have been increasing challenges to what constitutes facts and analytical interpretations of facts and data, and this is especially relevant in terms of climate change. There has also been a blurt ring of opinion and fact and an increasing volume of opinion, speculation, and politically motivated viewpoints that tends to drown out verifiable information. The authors note that the effects of these trends include the decline of civil discourse, the alienation and disengagement of citizens, the undermining of trust in public institutions, and the inability to take effective action to address significant social and political problems. Additionally, people can manifest an "optimistic bias" as it pertains to their own capacities to evaluate information online (Flanagin \& Metzger, 2010) despite evidence that their capacities can be "bleak" across grade levels and into the college years (Wineburg, et al, 2016). 


\section{Eco-Civic Media Literacy}

To help frame the challenges of reading and evaluating information sources about the divisive, complex sociocientific topic of climate change, we worked to integrate theories of ecolinguistics and civic media literacy along with a conceptual understanding of reliability source evaluation.

Ecolinguistics. Ecolinguistics marries ecology and linguistics to examine the relationship between language and the stories that groups of people tell and share about the interaction of organisms with each other and the physical environment (Stibbe, 2015). A primary goal of ecolinguistics is to analyze language patterns in texts to reveal the "stories-we-live-by" when it comes to environmental issues and perspectives (Stibbe, 2015). Stibbe explains this further:

...the stories-we-live-by are embedded deeply in the minds of individuals across a society and appear only indirectly between the lines of the texts that circulate in that society. They are therefore not immediately recognizable as stories, and need to be exposed, subjected to critical analysis, and resisted if they are implicated in injustice and environmental destruction. (p. 5)

How we interpret or analyze a "story-we-live-by" depends on our ecosophy, what Stibbe (2015) defines as a "a normative set of principles and assumptions about relationships among humans, other forms of life and the physical environment" (p. 202). Thus, it is essential for researchers or analysts to be clear about the ecosophy they bring to bear in their work. In this research study, the three of us share an ecosophy that values all living organisms, and we build from the scientific knowledge that anthropogenic (human-caused) climate change is occurring as we advocate for systemic, institutional, social, and individual changes that less negatively impact the planet.

With one's ecosophy in place, Stibbe contends there are three kinds of stories we need to discern: a destructive story which opposes the ecosophy, an ambivalent story, which aligns somewhat with the ecosophy, mixing benefits and drawbacks, and a beneficial story, which harmonizes with the ecosophy. Thus, we consider the stories "the goal of society is economic growth" or "individuals primarily want to maximize wealth" to be destructive and must be resisted because, left unchecked, these can foster the destruction of ecosystems. In contrast, a story that encourages behavior to protect diverse life systems (e.g., the goal of society is happiness and harmony among all living things) is beneficial and is to be cultivated and promoted (p. 17). Korten (2007) outlines several prevailing stories we have been living by, including a "prosperity" story that centers on wealth acquisition, a "biblical story" that emphasizes the after-life, and a "security story" that centers on military and police intervention and protection. Together these stories are destructive because they can "perpetuate injustice and lead to both alienation and environmental destruction" (Stibbe, 2015, p. 3).

Civic media literacies. Because ultimately our interest lies with the ways future teachers, with different beliefs and from different academic backgrounds discuss and deliberate ideas about the reliability of climate change information sources, we also appealed to perspectives that integrate media literacy with civic education. A civic media literacy perspective stresses the need for discussion and deliberation among groups of people (Hess, 2009; Hess \& McAvoy, 2014; Parker, 2006) and the use of key 
reading practices, such as asking questions about a source's authors and sponsors to detect biases, evaluating claims and evidence to discern erroneous reasoning, and examining how one's own beliefs, values, knowledge, and views affect one's meaningmaking (Baildon \& Damico, 2011). These skills are especially needed with digital information sources about climate change, a complex socioscientific topic, because it is based on core science principles, is challenging to solve, and is controversial with people possessing different views about whether anthropogenic climate change is happening and what needs to be done about it (Sadler \& Zeidler, 2004).

The National Association of Media Literacy Education (NAMLE) argues that media literacy education "requires active inquiry and critical thinking about the messages we receive and create" in order to produce "informed, reflective and engaged participants essential for a democratic society" (2007). Masyada and Washington (2016) draw from NAMLE to offer a model of civic education with an emphasis on conceptual thinking, which they define as "foundational ideas of civics... no matter the content that is being studied... [ideas that] include such concepts as liberty, equality, security, collaboration, and conflict, among others." Masyada and Washington also appeal to the C3 Framework created by the National Council for the Social Studies (NCSS), with its emphasis on student and teacher-led inquiry, to make central the posing and pursuit of critical questions, the use of different disciplinary perspectives (history, economics, geography, civics), the careful evaluation of information sources, and finding ways to communicate findings and take action. Dialogue and deliberation are essential to this entire process.

Reliability evaluation. The concept reliability is central to civic media literacy and the health of a democracy. We need to deliberate ideas and make decisions based on reliable, trustworthy information. To better discern accurate, reliable information from inaccurate, unreliable information, a conceptual understanding of reliability, along with a set of key procedures to evaluate reliability, is necessary (Damico \& Baildon, 2015). Table 1 outlines procedures and corresponding conceptual understandings to highlight that determinations of the reliability of any given information source needs to be a holistic assessment (see final procedural step).

The procedures outlined in Table 1 offer clear steps to help determine the reliability of information sources. Yet, given particular challenges in a post-truth mediasaturated world, there is also a need to consider larger conceptual frames that inform and shape reliability evaluations. Thus, we extend Stibbe's ecolinguistics framing of "stories-we-live-by" to consider "reliability stories-we-live-by" -- how people determine whether or not information sources are reliable and trustworthy in terms of larger cognitive or conceptual frames that shape their sense-making. Like other "stories-welive-by", these reliability stories are "not immediately recognisable as stories, and need to be exposed, subjected to critical analysis, and [possibly] resisted" (Stibbe, 2015, p. 5).

\section{METHODS}

Our larger research project centers on the ways preservice teachers evaluate the reliability of climate change sources. We chose climate change as our research topic because it is a "mega problem" of the 21st century (Martin, 2007), and we chose 
preservice teachers to be participants because, as Desmond Tutu, Archbishop Emeritus of Cape Town, South Africa, has argued, there has been a "tepid response of school-age and higher education to the global warming challenge" (2010, p. xvi).

This project includes two key phases: a classroom-based activity and follow-up paired interviews. In the first phase, secondary-level pre-service teachers from different Table 1

Key Procedures and Conceptual Understandings for Evaluating Reliability

\begin{tabular}{|l|l|}
\hline Procedure & Key Conceptual Understandings \\
\hline $\begin{array}{l}\text { Evaluate } \\
\text { provenance }\end{array}$ & $\begin{array}{l}\text { 1. Author background, expertise, experience affect their competence to speak } \\
\text { about particular issue (depends on issue they discuss and their experience with } \\
\text { it). } \\
\text { 2. All authors are biased or have limited views but we must determine if the } \\
\text { bias is acceptable or if it should disqualify them. } \\
\text { 3. Disclosure which states one's background, interests and positions is } \\
\text { important. If not stated, can do background check. }\end{array}$ \\
\hline Assess purpose & $\begin{array}{l}\text { 1. All sources written/created with some purpose in mind. } \\
\text { 2. Some purposes explicitly stated while others may be vague, implied, } \\
\text { hidden or not easily discerned. }\end{array}$ \\
$\begin{array}{l}\text { 3. Some purposes more trustworthy than others (e.g., inclusive, sincere, } \\
\text { respectful, balanced purposes more trustworthy than efforts to mislead, deceive, } \\
\text { or solely promote self-interest). }\end{array}$ \\
\hline $\begin{array}{l}\text { Analyze content and } \\
\text { cross reference }\end{array}$ & $\begin{array}{l}\text { 1. Claims and evidence must be evaluated for accuracy. This requires } \\
\text { evaluating reasonableness, if content fits with what is already known, what } \\
\text { other sources say, etc. } \\
\text { 2. Need to check content for errors, bias, and tone (e.g., if emotive, one sided, } \\
\text { advocacy focused, etc.) to determine if reliable as a source of information. } \\
\text { 3. Need to corroborate information, check to see if it is consistent with other } \\
\text { sources or refuted by other sources. }\end{array}$ \\
\hline $\begin{array}{l}\text { Make determination } \\
\text { of reliability }\end{array}$ & $\begin{array}{l}\text { judgment of reliability because informed conclusions and decisions require } \\
\text { reliable information. }\end{array}$ \\
\hline
\end{tabular}

SOURCE: Damico \& Baildon (2015)

disciplinary backgrounds who were enrolled in a content area literacies course completed a multi-step reading activity to evaluate the reliability of multiple online sources about climate change (Damico \& Panos, 2016). Two of us worked with the course instructor to help facilitate the activity. The second phase of the study is our focus in this article. At the end of the semester we invited all 65 participants from the first phase to extend their thinking about the reliability of online sources about climate change through paired interviews with another student from a different content area, a type of cross content area discussion (e.g., math and science) that has been shown to increase "dialogue across difference" (Arksey \& Knight, 1999). Ten students accepted our invitation and we intentionally set up the interviews by pairing students with 
different disciplinary backgrounds and, to the extent possible, different climate change profiles. We then conducted five paired interviews and selected three of these interviews for closer analysis (the other two pairs of students were at different points in their coursework or had decided to not become teachers).

In terms of their climate change beliefs, the study participants completed an online version of the Yale Program on Climate Change's Six Americas survey as part of the first phase of our research study. This survey assesses Americans' beliefs, values, motivations, and attitudes toward climate change policy on a continuum of six unique profiles (Leiserowitz, Maibach, Roser-Renouf, \& Smith, 2010; Leiserowitz, Maibach, Roser-Renouf, \& Smith, 2011; Leiserowitz et al., 2016; van der Linden, Leiserowitz, Feinberg, \& Maibach, 2015). These profiles (alarmed, concerned, cautious, disengaged, doubtful, and dismissive) span an orientation to climate change from alarmed, where individuals recognize that anthropogenic climate change is occurring and that urgent, comprehensive action is necessary, to dismissive, where individuals deny the validity of the scientific consensus and believe that policy and regulation related to anthropogenic climate change should be actively resisted.

As with the results of any survey, we acknowledge these six categories are necessarily limiting and incomplete. The students are more than their climate change belief orientations and our goal is not to reduce each person to a profile. All readers are complex and read from a range of different social locations or subject positions that reflect their beliefs, values, and backgrounds. Nonetheless, the survey results provided a way to help us explore what might happen when students with different climate change profiles jointly discuss and deliberate climate change sources. Figure 1 shows each participant pairing, including their disciplinary perspectives and climate change profiles. The task for the paired think-aloud interview protocol was to jointly view the two sources (described in detail in the following section) and to discuss whether each source was reliable for considering what, if anything, to do about climate change.

Figure 1

Interview Pairs 


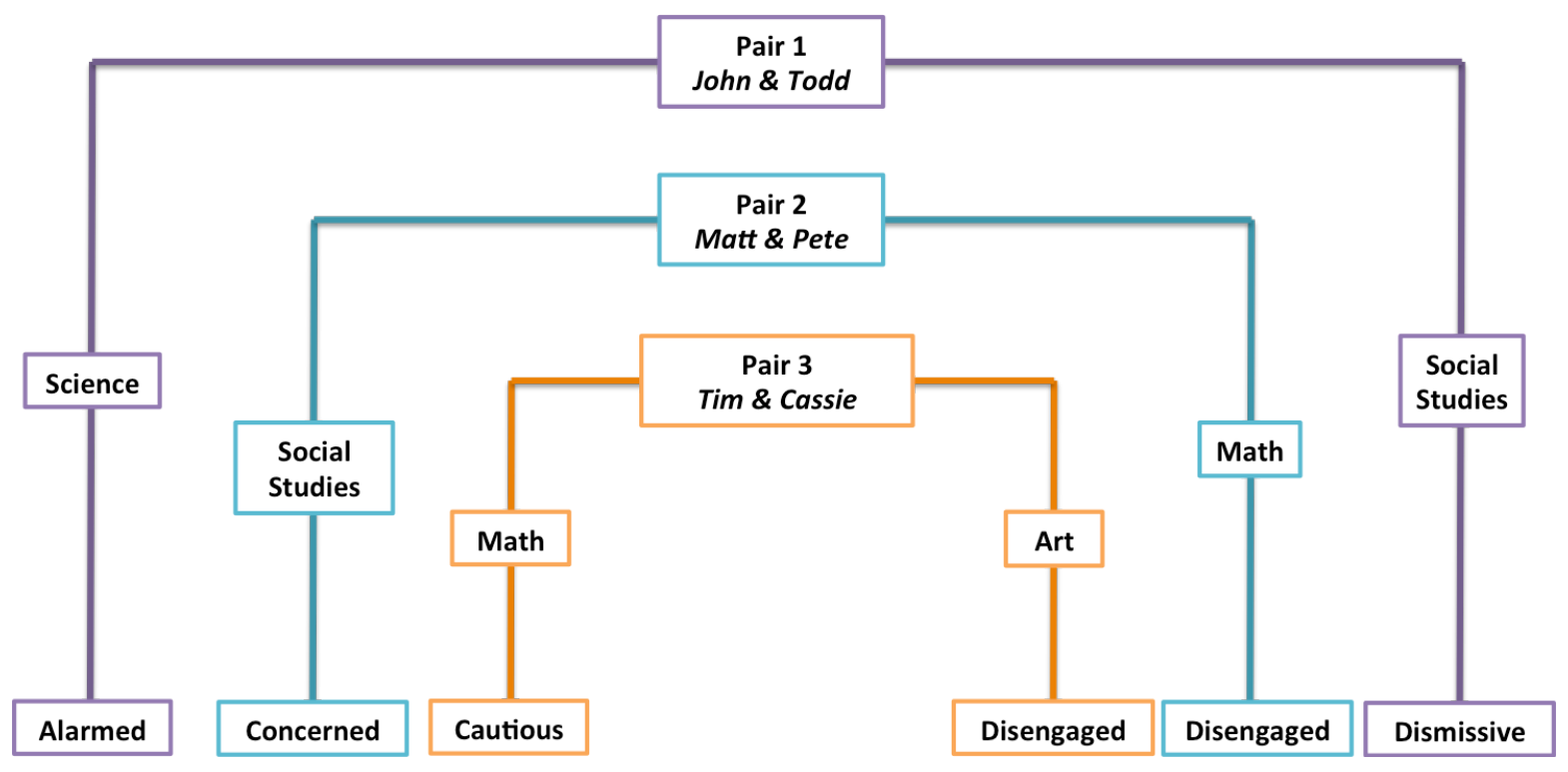

SOURCE: Damico, Panos \& Myers (2018); pseudonyms are used throughout.

Two of the authors audio and video recorded all three 4560 minute interviews in small meeting rooms at a university. We began the interviews by reminding participants of their climate change profiles and then asked them to view each source one at a time, to discuss whether this source was reliable for determining what, if anything, should be done about climate change. Interviewers asked minimal or clarifying follow up questions (e.g., what might make this source more or less reliable?)

\section{Video Sources}

Two online videos were selected based on their diametrically opposed perspectives on climate change. The first video Global Warming: Glaciers (2006) was produced by the libertarian think tank the Competitive Enterprise Institute which advocates "advancing the principles of limited government, free enterprise, and individual liberty." This video source, published on YouTube, is representative of a dismissive text, given that it contains characteristics of science denial such as fake experts, logical fallacies, impossible expectations, cherry picking, and conspiracy theories (Washington \& Cook, 2011; Cook \& Jacobs, 2017). In the one minute video, a voiceover narration and a succession of visual cues argue scientific experts' findings and concerns about an increase in carbon dioxide in the atmosphere are not only suspect but also overlook potential benefits to humanity. From an ecolinguistic perspective, this is a destructive story (Stibbe, 2015) because it challenges the scientific consensus.

The second video source, titled, "What is fossil fuel divestment and why does it matter?" was produced by regular contributors and environmental activists for The Guardian's "Keep it in the Ground" initiative in 2015. It was published on the leftleaning and Pulitzer Prize winning online news site. The two minute and forty second video represents an alarmed perspective and represents what Stibbe (2015) would call a beneficial story, as it offered a policy proposal (divestment) aimed at addressing climate change as a social and economic issue. We acknowledge there are notable distinctions 
between these two sources and, to some degree, they are not directly comparable. The first distorts and manipulates scientific evidence while the second relies on the scientific consensus to present a policy solution.

We selected these two sources for three primary reasons. First, these sources represent the type of sources that commonly circulate about climate change; it is less likely, for example, the students (or the three of us) would come across sources with only scientific information or research as in an academic journal. Second, the science and politics (such as policy proposals) of climate change often commingle in more popular press sources. This is the case here. While the first source, for example, appears to focus solely on the science, it was created by the Competitive Enterprise Institute, which has a clear economic and policy agenda. Third, both sources address (or provide an answer for) the specific task the students were asked to complete- i.e., evaluate the two sources to help determine what, if anything, needs to be done about climate change.

\section{Research Questions}

We began with a straightforward set of research questions: What did each pair of students discuss? What did they focus primarily on? And in what ways did they agree and/or disagree with each other? This analysis led to a core follow-up question: What reliability stories do preservice teachers construct (live by) as they evaluate climate change sources?

Drawing on approaches to discourse studies (Lester \& Paulus, 2014) that account for an ecolinguistic approach to understanding the stories we live by (Stibbe, 2015), our team of three researchers engaged iteratively in (1) the development and repeated readings of transcripts of each interview; (2) selection, organization, and identification of patterns; (3) generation of explanations beyond quantifying patterns (the reliability stories we describe in our findings section); (4) noting variability across the findings; and (5) reflexive and transparent documentation of our claims through shared GoogleDocs files. We also recognize, again, that our approach to this study is based within our shared ecosophy (Stibbe, 2015). Finally, the development of a manuscript and writing are considered an essential part of the research process (Richardson, 2002).

In the following section we employ the reliability evaluation framework (as found on Table 1) to consider what happened when each pair of students evaluated the two sources. Next, we outline the three reliability stories we discerned in our subsequent analysis.

\section{RELIABILITY EVALUATIONS: INITIAL FINDINGS}

\section{Pair 1: John and Todd}

In previous work, we have documented the ways John and Todd have evaluated the two web sources from their diametrically opposed climate change profiles (alarmed and dismissive) and distinct disciplinary backgrounds in science and social studies/history (Damico, Panos \& Baildon, 2018). While the other two interviews were marked by agreement and building ideas around reliability, John and Todd's conversation was collegial but contested.

As they began working with the first source, John expressed his concern with the language of the video, focusing on the emotional nature of an appeal that uses "words 
like supposedly and scare and...talked about children.” Todd agreed with this assessment of an emotional appeal and articulated that this indicated the source's purpose was "to say that global warming is not an issue, but...that's one...well-made perspective from that side of that aisle." They, however, disagreed on the way purpose and provenance impact reliability. For John, "if I'm sold on the logo they use at the bottom and how many times they show trees, then I feel like the emotional appeal isn't something I should necessarily go on." While Todd argued that with this source, "I could feel confident that it was a reliable enough representation" and noted its usefulness in providing some data and evidence to support this argument, John noted that he "tries to distance myself from [the emotional appeal]" instead favoring more data to interact with, including disconfirming evidence and "more statistics." Todd agreed about the need to see more studies.

With the second source, John and Todd explored concerns they had with its content. Todd criticized the source for not offering an alternative to fossil fuels and contended that climate change "dismissives" are reasonable people; they aren't opposed to alternative energy sources, they just want equitable prices and availability. John acknowledged this source aligned with his beliefs and that he trusted this source, but that he did not agree with divestment as the best strategy to combat climate change (and noted that solar panels are reaching market parity with fossil fuels). Together they critiqued some of the claims and evidence provided in the video related to historical uses of divestment (such as during apartheid in South Africa), with John claiming that "was kind of a stretch" and Todd stating that it was a "very emotional tack." However, both struggled with determining the real purpose behind divestment and how it would impact the economics of the fossil fuel industry and the fight against climate change. This time, Todd articulated a desire for more "data even if I'm believing this that divestment actually works" while John grappled with the goals of the movement: "I just don't feel like many people would be sold on this type of strategy." They also returned to their concerns with the source's purpose, with John again noting, "its just kinda the frame game again" and Todd reiterating its usefulness for an alarmed perspective.

John and Todd examined provenance, purpose, and content with both sources, but were at distinct odds in their conclusions about reliability. Even while agreeing on the source's purpose, their sense of what that might mean for reliability differed. Overall, reliability for Todd entailed an accurate representation of a perspective about climate change not an accurate representation of established content or understandings about the topic. This led Todd to deem the first source a "reliable representation" of a dismissive view and the second source a "reliable representation" of an alarmed perspective. Reliability for John, in contrast, was related primarily to results of evidence-based science for both sources.

\section{Pair 2: Pete and Matt}

Pete, a math major with a cautious profile, and Matt, a social studies major with a disengaged profile (although he was uncomfortable with the "disengaged" label during the interview), evaluated provenance, assessed purposes, and analyzed content as they worked to determine the reliability of the two sources.

With the first source, they focused on provenance and purpose, working to discern goals of the Competitive Enterprise Institute, the author or organization sponsoring the source. After Pete noted the "lack of information" about this Institute was 
"kind of suspicious," the two identified that the word enterprise meant economics and profits. This led to more sustained concerns about authorial techniques (e.g., a graphic used in the video where magazines flip over), insufficient evidence to support claims and, in Matt's words, questions about "what are they really trying to hide." Matt also added, "I guess the biggest thing for me, is that apparently, they assume that I don't already trust the news organizations they want to smear [laughs] but I do. I already read the Washington Post... and trust that more than whoever this narrator is."

In checking content for errors, Pete disputed the claim in the video that "carbon dioxide is life," stating the basic fact which he is "pretty sure every scientist knows" that "carbon dioxide in large quantities for human beings is deadly." Matt brought this back to authorial techniques, the inclusion of "a nice picture of a tree" and the lack of "corroboration" with other people and sources. Pete also pointed to potential problems with the video just including the titles of articles from scientific studies, which "could be misleading" because they are intended to "grab your attention." Drawing from his experience in a statistics course, Pete also pointed to problems with misrepresentations in statistics, such as the use of small populations or small sample sizes, which can be used to distort actual findings.

With the second source, this interview pair focused less on source provenance (looking closely at author's background, expertise, and experience). Matt offered a highlevel assessment of its purpose, stating it was "all about economics" and noted "they weren't trying to convince us of anything" because the source "already assumed some things." Pete joined in, noting that the audience already believes climate change is happening and "needs to be fixed." In terms of analyzing content, Pete "didn't like" that "they put the entire blame on the fossil fuel industry" and pointed out that "really it's everybody's responsibility not just the fossil fuel [companies]." Matt disagreed, offering a more structural analysis, posing the question, "So, who's to blame if it's not the oil companies?" and noting the limits of individual agency ("we're pretty much forced to buy gas"). The two students explored their different perspectives across the next sixteen conversational turns with Pete maintaining a perspective that kept individual agency (and culpability) in the foreground while Matt stuck to his structural critique.

Next, the two endeavored to develop an understanding of what "divestment" meant. Pete led the exchange, offering a summary of his take on the main claim of the video. "I think they were trying to say that as you take money away from these sort of companies they're forced to make changes in order to bring back that money they've lost... taking it away from the problem and putting it towards the solution." This led Pete to make a claim that "we still need fossil fuels because we have no alternative yet. If we had an alternative, then I'm pretty sure people would be all for it." He also brought up the author's use of evidence by analogy in the video -- i.e.,the comparison to the divestment campaign in apartheid South Africa. While Pete found the analogy problematic ("Africa isn't nearly as industrialized as the United States, let's be honest"), Matt clarified that what was being compared was "the process of protest" which "put global pressure on South Africa to stop apartheid."

Through this exchange Matt reflected more on the purpose and audience of this source. "Now [that] I think about it, I don't know. I don't know if we were even their target audience. Because we aren't really, I don't have, I don't have money invested in these companies. Maybe that's why they didn't get too specific? Because maybe we're 
supposed to go out and convince more powerful people?" Pete countered, contending that the audience was "the common person" because "they tried to explain what disinvestment was." He also acknowledged why the analogy to apartheid in South Africa was somewhat elusive to him, noting that he didn't remember "that particular part of history ever being taught to me." The two continued to focus on the economic argument in the source. Matt

noted he liked "the focus on economic policy and larger institutions instead of just individual people, because it's kind of just the world we live in. That you kind of have to target the higher ups to really make a change."

\section{Pair 3: Christy and Tim}

Christy, an art major with a disengaged climate change profile, and Tim, a math major whose profile was cautious, evaluated the two videos by mostly agreeing with (and building on) each other's views of reliability. With the first source, Tim immediately launched a discussion of its provenance and purpose, wondering who the Competitive Enterprise Institute was, with Christy joining him, asking, "competitive enterprise, does that mean, that you like, help companies?" They both identified this source's purpose as political. Tim also cross referenced the source to the classroom activity (that was part of the first phase of the research study), noting, "I remember in like the first activity with this was that one of the, of the sources was from another institute like very heavily politically backed...thinking along those lines I was just like, it seemed much more like a political ad." Christy agreed that this seemed like the "same propaganda stuff." This led them to both be concerned about the tone and non-scientific content of the source. Christy expressed concerns that "they weren't using just subtle language to describe other people. They were much more aggressive." Tim built onto that statement by adding "there were also a lot of leaps between a) their data and b) what they actually said."

Before viewing the second source, Christy and Tim briefly discussed this video's provenance, considering the authors and their ties to The Guardian and roles there. Christy launched this by asking "what's this list of people? Are these all the authors?" Tim followed up by wondering aloud (as Christy clicked on links) "it says here that [they are] journalists." Their close reading of authors' names and exploration of the hyperlinks included examining bolded text (Christy: "Why do they have this name in bold? Do you know this guy?") and expressing confusion about the exclusion of links on the page (Todd: "I thought there was gonna be a link"). Todd also commented that he found the authors "were pretty open" about their goals related to divestment. Christy noted that there was "a lot of visual propaganda" and that it was "prettier" than the first video.

In terms of the content of the video, Tim also highlighted that climate change was treated as a social issue rather than a scientific issue: "it's not the science anymore, it's a social issue cause like there's so many different opinions about it." While he acknowledged his own lack of knowledge about divestment, he thought it could make an "economic impact" in particular in the context of "the RFRA (Religious Freedom Restoration Act) thing in Indiana, divestment is one of the things that came up, was that like, companies were pulling their money out of Indiana. And it's like hold on let's, we kind of need that." Christy agreed that she had heard of divestment but did not know much about it. She then stated, in a return to provenance, that she trusted The Guardian 
video because "at least it seems sort of familiar." She agreed with Tim, however, that the source didn't explain divestment enough for her. Tim remarked that this video was "supported a little bit better than the first video.... I don't remember them talking about having any sort of, specific, like, scientific data." Both participants recognized that the main claim of the video was related to the viability of divestment, and struggled with whether the video supplied the evidence to back that up given their own lack of knowledge (although Tim's reference to the then-current connection to RFRA suggests a more robust understanding of the aims of divestment).

While these two pre-service teachers had different subject backgrounds and climate change profiles, they tended to confirm and build on each other's ideas as they evaluated the reliability of the two sources. Together, they identified their lack of background knowledge at times, but each emphasized different aspects of the sources to evaluate reliability, considering provenance, purpose, content, and cross referencing to other texts and current events. While overall, Tim wanted more information, especially information that could be presented in a more "scientific manner," Christy emphasized aesthetic criteria and the production quality of the videos. For her, information "just [goes] into the background... you don't necessarily pay attention to it." Instead, reliability depended on being able to "know who's telling me and if I trust them," and whether the source "connected" to her in some way "based on what I already believe."

\section{Summary}

Looking across these three interviews there is clear evidence the preservice teachers considered provenance, purpose, and content of the two sources in their reliability evaluations (Table 1). There were also times when they indexed their disciplinary backgrounds in their sense-making. For example, Pete, as a mathematics major, drew from his experience in a statistics course to discuss how statistics can be manipulated, and that this necessitates a critical stance toward numerical data. And Matt, a social studies major, drew upon his historical knowledge of apartheid in South Africa to clarify the type of climate change comparison being made in The Guardian video. There was less evidence of students directly indexing their climate change beliefs in the interviews, though some exchanges between Matt and Todd were exceptions (see Damico, Panos \& Baildon, 2018 for more extensive treatment of this).

While these three pairs of students seemed to skillfully move through reliability evaluation components outlined in Table 1, through our ongoing analysis, along with continued reading about the potential intersection of ecolinguistics with civic media literacy, we began to discern what struck us as an extension of Stibbe's (2015) ecolinguistics framing of "stories-we-live-by." This led us to identify what we call "reliability stories-we-live-by" - that is, how people come to deem information sources to be reliable and trustworthy or not. Again, these stories are "not immediately recognisable as stories, and need to be exposed, subjected to critical analysis, and [possibly] resisted" (Stibbe, 2015, p. 5). While we came to see these reliability stories in the preservice teacher interviews, it is without criticism of these students. We find ourselves living with these reliability stories as well.

\section{RELIABILITY STORIES}


Three reliability stories that the future teachers took up in their paired discussions were: 1) needing the "other side" represented, 2) wanting more information or evidence to support an argument, and 3) reasoning through one's own identity and perspectives. While there is evidence of each reliability story with each of the interviews, some reliability stories were more pronounced in one pair than another. These three stories were also more prevalent when the students discussed the first source from the Competitive Enterprise Institute. Overall, we deem these findings a cause for potential concern, especially when viewed through ecolinguistics and civic media literacy lenses and in response to the pressing problem of climate change.

\section{Reliability Story \#1: Wanting the "Other Side" Represented}

Across the interviews there was a perceived need that the two sources needed to have another (or "the other") side represented. Pete and Matt, for example, stressed that opposing views had to be presented in a balanced way and they suggested that reliable sources present information within the two sources to fairly represent opposing views on climate change. They thought that evidence within the source could be provided by "interest groups," others who have done studies and have data based on research (e.g., "professors"), along with people "on the other side of the continuum." Desiring balance in the presentation of perspectives in the sources, Pete argued that it would have been better if the narrator of the first source had not been dismissive of the opposing side's claims. Pete argued that "in a debate, no matter if you disagree with someone, they have the right to disagree with you. So, you have to at least honor that in some way." Matt agreed that opposing views had to be acknowledged, while Pete concluded that, "Yeah, [there has to be] acknowledgement of the person's opinion even if you think it's wrong." For these two pre-service teachers, the climate change "debate" required a fair and balanced representation of "both sides" of the debate. This debate framing was most pronounced with John and Todd. While John, a science major, emphasized the "99-1\% scientific consensus" on the human causes of climate change, Todd argued that there's still credible doubt and "each side has to be given merit." Todd went on to claim that while evidence may suggest more carbon dioxide in the atmosphere, there is debate about whether this is a "good thing" or a "bad thing."

It does bear noting that seeking the "other side" from the first source would be to search for scientific consensus (a laudable pursuit). Yet, the primary concern here is when the goal to obtain the "other side" is intended to achieve a balance. This reliability story of "balance" emphasizes a seemingly salutary goal of hearing "both sides" of an issue, regardless of provenance or purpose, but it is misapplied when examining something that has been scientifically settled (Baildon \& Damico, 2011; Oreskes \& Conway, 2010). In the book, Merchants of Doubt, Oreskes and Conway (2010) detail the ways a small group of scientists, working in concert with political advocacy groups, misled the public about well-established scientific findings related to tobacco, acid rain, the ozone hole, DDT, and climate change. One potent strategy of these misinformation campaigns was to frame the issue in terms of a debate, suggesting there was still doubt or uncertainty about the scientific findings. As a result, competing sides or perspectives merited inclusion and consideration. The effect was the creation of a false equivalency between established scientific findings (and consensus) and more extreme minority scientific views about each of these issues (e.g., tobacco smoke is not that harmful). 
One byproduct of these practices, as we see from our interviews, is the development of a particular kind of reliability story, one in which designations of reliability are based on the view that sources need to have "the other" side represented. Again, while a seemingly beneficial story, one that aligns with civic media literacy perspectives, this could also be what Stibbe (2015) calls an ambivalent or even a destructive reliability story when the "other side" is a distortion or refutation of established scientific evidence or calls for an undesirable "balance."

\section{Reliability Story \#2: Wanting More Evidence to Support an Argument}

A consistent finding across the three interviews was the view that the acquisition of additional supporting information or evidence would make either or both of the sources more reliable. While this stance is similar to reliability story

$\# 1$, which also calls more additional information, with reliability story \#2, the issue is the need for more supportive information rather than an opposing perspective to attain some illusory balance.

The story that emerged from the pre-service teachers' paired discussions was that reliability depended on whether or not enough information was provided to support the main claims made by the video sources rather than an evaluation of the credibility or accuracy of the information itself. We see evidence that the pre-service teachers deemed sources to be reliable if they had enough information, especially information corroborated by other sources and studies. With the first source, John, for example, noted, "I would have liked to see more data" and "I wish they would have told me something about those studies or like what was wrong with the studies...just something that I can hang my hat on a little more to say no there's less $\mathrm{CO} 2$ in the atmosphere, something more concrete that I can believe, than just this isn't happening." Tim also emphasized the need to "get as much information as possible," and that "no matter what I read, I'm gonna dig deeper into it." Since there were "so many opinions" about climate change, he noted that his initial stance was one of skepticism, which led him to seek more information about different perspectives.

Reliability story \#2 was also a function of the type of information presented. Tim especially desired information that could be presented in a more "scientific manner." It had to at least "sound" scientific. Similarly, Pete stated that, "If it [first video] had, maybe given out more names and actual articles, stuff like that, stuff you know where I could read about these scientific, you know, ideas, then maybe it'd be a little more convincing." In other words, even though the video was dismissive of the scientific consensus about climate change, if it had provided more information to bolster its case he would have deemed it more reliable. For Christy, it was a matter of wanting information about this video's sources so she could corroborate the claims in the video, while Matt wanted more quantitative data, saying "at some point [the narrator] needs to say, use quantitative data is always helpful, numbers, like that's always useful, instead of just saying like, this is what I think."

The story that emerged from the interviews was one of having more information that would convincingly support or corroborate the perspectives and information in the videos. They wanted the sources to identify and cite other studies and information sources upon which claims were based. These prospective teachers, however, run the danger of falling prey to how the Internet works as a "self-sustaining reference system" 
(Burbules, 2001) where many of the news articles, studies, and information presented as evidence, or used to "corroborate" information in sources, typically comes from other online information sources with similar agendas and perspectives. In other words, simply having more information, whether it is from other studies, presented in a "scientific manner," or offered as quantitative data may be just as unreliable as the source being evaluated.

Again, the seemingly laudable pursuit to be "better informed" by having more information may actually result in reinforcing and strengthening misinformation or unreliable information sources. As a result, rather than being a beneficial story, the expressed need for more information can be an ambivalent or a destructive story. Living in the Internet age with boundless information streams about almost innumerable topics makes it easy to locate information sources to corroborate or echo a point of view. Accomplishing this task is often a few keystrokes or finger swipes away, but actually requires that claims and evidence be carefully evaluated for accuracy and that content is checked for errors and bias.

\section{Reliability Story \#3: Reasoning Through One's Own Identity and Perspectives}

The pre-service teachers in this study often referenced their identities, in terms of their academic majors area and, to a lesser extent, their climate change profiles, to evaluate the two video sources. For example, Christy talked about being an art educator and evaluating the sources with an "artistic view" that drew on particular aesthetic criteria, such as whether it was "stylish," "had better effects," and the extent to which it used visual effects and was "put together to make us feel a certain way." She also noted that she was a busy student and suggested that this accounted for her being "disengaged" in regards to climate change. Tim supported these assessments and noted that Christy's art background resulted in her focusing on the visuals used in both sources.

During the interview, Christy and Tim also discussed the need for texts to "connect" to them as readers. Tim said he felt "a little separated" and "disconnected" from The Guardian video because he did not have investments. Similarly, Christy said she didn't trust data unless she knew "who it's coming from and where" and noted, "It's almost a Catch 22, cause you already have to have some belief in order to believe what it is that you're reading... Or you have to trust the person who's telling you, or the site that's telling you." This sense of connection and trust in the sources depended on what they already knew or believed. Pete (math; disengaged) and Matt (social studies; concerned) also noted the issue of "connection" while discussing the first video. For Pete, the narrator of the video "wasn't trying to connect with us at all," which prompted Matt to raise the issue of trust by noting that the video "smeared" the Washington Post, a trusted news source for him.

John acknowledged his science and chemistry background as he made sense of the first source: "That's kind of why I wanted more data on the first one... [about] concentrations of $\mathrm{CO} 2$ in the atmosphere and how this will change, or what those changes [might be]... That would be a little more believable for me." His conceptions of reliability emphasized evidence-based scientific inquiry, grounded in accurate data, that yielded science-based verifiable facts. Similarly, his interview partner, Todd, responded to the first source by acknowledging his own background as a history major: "As a historian... I don't want to see if the source is true. I want to see who, [and] what is it 
trying to tell us" contending that historians use evidence to support arguments. Todd articulated that sources were reliable when they accurately represented a given perspective as opposed to requiring factual accuracy or authorial expertise. Todd said he "does not consider if something is true" given that in his identity as a history educator he does not "work in the truth business" (Damico, Panos \& Baildon, 2018).

As Stibbe (2015) argues, identity is a type of story that people tell about themselves but it is also constructed as part of larger social forces that individuals may or may not be aware of. Readers employ a range of identity resources (e.g., values, beliefs, background knowledge, etc.) in evaluating information related to gender positions, sexual orientation, cultural backgrounds, social class, race, nationality, religion, ideological perspectives, and professional identities (Damico, Baildon, Exter, \& Guo, 2009). These social locations and resources can be a double-edged sword, however. In research on motivated reasoning, Hart \& Nisbet (2011) found that, embedded social identity cues interacted with political orientations to amplify public polarization on the controversial science issue, climate change. Furthermore, neither factual knowledge about global warming nor general scientific knowledge was associated for support for climate mitigation policies. These findings demonstrate the important role motivated reasoning plays in the interpretation and application of messages discussing scientific issues. (p. 15)

Reading from one's identity position(s) can be a problem, since individuals are motivated to trust sources that align with their pre-existing beliefs (selective exposure) and interpret events in line with those beliefs (selective perception). (Baildon \& Damico, 2011; Manjoo, 2008). It may reinforce certain assumptions, viewpoints, or stories that can possibly be destructive, ambivalent, or beneficial (Stibbe, 2015), so it is imperative that we be more aware of how these "stories" work to shape both understandings of ourselves and the world. One of the students, Christy, demonstrated movement in this direction when she discussed her typical process when reading and evaluating the web videos:

I don't know if it would have come across my path normally, and if it did I don't know that I would pay that much attention to it. I would just go, ok. I don't know how much I would commit... Maybe if I was seeing it every single day on my news station, I would be like, oh what is this about? But otherwise it's just gonna be noise for me. I've gotten so used to blocking out these things. That kind of stuff. You know?

Christy went on to highlight how sources that might challenge her views or provide new information that she was not aware of might go into "the background" and "you don't necessarily pay attention to it...because we're bombarded with information." Here, we see evidence of Christy identifying her own reading tendencies, generally bypassing or "blocking out" information sources that do not align with her own pre-existing beliefs. This acknowledgement of one's own biases is a critical step. Greater reflexive humility would then include identifying these tendencies and biases, as well as the "stories-welive-by" that shape how we think about environmental issues and the reliability of information. An important eco-civic media literacy practice is reflexively interrogating one's own ideological beliefs, assumptions, biases, and gaps in understanding that these inevitably entail. 


\section{IMPLICATIONS}

These three stories seem to have a striking common-sense quality to them. Of course, getting multiple perspectives on an issue (i.e., other sides) is important, and acquiring more information or data to support an argument is essential, and acknowledging one's own social location(s) as a reader is a valued practice. Yet, making sure we include "the other side" is not useful if the other side is based on erroneous information or when the goal is to achieve an objectionable "balance." Similarly, the acquisition of more information to support an argument is not worthwhile if the argument is faulty or the information untrue. Moreover, it is easy to locate additional information to support just about any perspective or argument. Finally, it is not enough for readers to acknowledge their backgrounds and perspectives given how easy it is to read with one's own perspective and social locations. Thus, these stories, like all stories we tell ourselves, merit scrutiny. For example, a key next step is asking and exploring what "other side" or additional information needs to be considered and why. While there is no shortage of information on the Internet that denies the scientific consensus about climate change, overwhelming scientific evidence points to human-caused climate change. Yet, there is a need to seek out additional information about policy proposals to address climate change, such as divestment (e.g., why a proposal for divestment might be better or worse than other proposals). There was some evidence of the students in this study doing this, though most of them seemed unsure what divestment as an economic and political strategy meant, which complicated this aspect of their conversations. Also, as part of reasoning through one's backgrounds and perspectives, it is crucial to acknowledge the limitations of one's understandings about a topic or information source and to identify what one needs to know. It was not clear, for example, that all the students knew there was a scientific consensus that human-caused climate change has been occurring. There was some evidence, especially with the second source, of the students identifying the need for them to learn more about divestment as a political and economic strategy.

In addition to implications about how we might think in general about examining reliability stories, this study points to questions more specific to preservice teacher education, and sets the stage for more intensive, longer-term inquiries. For example, we considered their academic disciplines and climate change profiles, yet they brought more varied and complex backgrounds, experiences, and identities to the interviews. The potential impact of these other social locations might more likely be discerned through in-depth follow up interviews and additional research tasks. Another area for more focused inquiry could be more explicit connections to the students' work as future teachers. The interview task did not ask the students to consider how they might teach climate change in their future classrooms. Instead, the task was to discuss whether each source was reliable for considering what, if anything, to do about climate change. Nonetheless, as university students in one of their required education courses, one of their core identities in the study was future teacher. Trying to gain a deeper understanding about the students' instructional ideas related to climate change (and other complex and politically charged topics) would be useful. This could include their thoughts about how they might negotiate the challenges of teaching about climate change 
in different kinds of school settings, such as those in support of or opposed to the scientific consensus.

In this vein, findings from this study point to a need for more attention in preservice teacher education to helping future teachers figure out how to work with complex topics and how to facilitate dialogue across different perspectives. This is especially important in a post-truth age when so many different perspectives about complex socioscientific issues such as climate change circulate in society and media and are likely to surface in classrooms. One way to address this challenge is to bring experienced classroom teachers into university classrooms to highlight how they have addressed these kinds of issues. Preservice teacher educators can also use a range of webbased resources to highlight the work of others invested in cultivating climate change dialogues. 1

\section{CONCLUSION}

We all make countless reliability decisions daily, determining who and what to trust and who and what not to trust. The escalating ubiquity of networked information technologies in our lives means many of these reliability decisions involve digital online sources. Thus, we need to continue striving to better understand how we make sense of these sources, especially when it comes to significant socioscientific topics like climate change. In a democracy, this striving needs to involve people across different backgrounds and perspectives discussing and deliberating their sense-making (Hess, 2009; Hess \& McAvoy, 2014; Parker, 2006). This was the intention for the interviews with the three pairs of preservice teachers who discussed the reliability of climate change sources across their differences in academic subject matter backgrounds and climate change beliefs.

Issues of reliability cut across all academic disciplines and complex social and political topics are inherently multi- if not transdisciplinary and involve engaging with and deliberating among a range of perspectives (Baildon \& Damico, 2011). Ultimately, a core media literacy goal is to help ensure all of us as readers and citizens across age levels and from different backgrounds are more equipped to question and challenge all types of media sources. Evaluating the reliability stories we are each living by can be an essential part of this process.

\section{REFERENCES}

Arksey, H., \& Knight, P. T. (1999), Interviewing for social scientists: An introductory resource with examples. Thousand Oaks: Sage.

Baildon, M., \& Damico, J.S. (2011). Social studies as new literacies in a global society: Relational cosmopolitanism in the classroom. New York, NY: Routledge.

Bartels, L. M. (2009). Economic inequality and political representation. The unsustainable American state, 167-96.

Burbules, N. C. (2001). Paradoxes of the Web: The ethical dimensions of credibility. Library Trends, 49(3), 441. 
Competitive Enterprise Institute (2006). Global Warming: Glaciers. Video. https://youtu.be/Wq_Bj-av3g0

Cook, J., \& Jacobs, P. (2017). FLICC: the five traits of science denial. Retrieved November 17, 2017 from https://www.youtube.com/watch?v=WgsjiWpptHw

Damico, J.S., \& Baildon, M. (2015). Rethinking reliability after students evaluate a Facebook page about health care in Singapore. Journal of International Social Studies, 5(1), 51-63.

Damico, J.S., Baildon, M., Exter, M., \& Guo, S.-J. (2009). Where we read from matters: Disciplinary literacy in a 9th grade social studies classroom. Journal of Adolescent \& Adult Literacy, 5(4), 325-335.

Damico, J. \& Panos, A. (2016). Reading for reliability: Preservice teachers evaluate the reliability of web sources about climate change. Journal of Adolescent and Adult Literacy, 60(3), 275-285.

Damico, J., Panos, A., \& Baildon, M. (2018). "I'm not in the truth business": The politics of climate change with pre-service teachers. English Teaching: Practice and Critique, 17(2), 72-89.

Damico, J., Panos, A., \& Myers, M. (2018). Digital literacies and climate change: Exploring reliability and truth(s) with pre-service teacher educators. In E. Ortlieb, E. Cheek Jr., \& P. Semingson (Editors) Best Practices in Teaching Digital Literacies, in (series) Literacy Research, Practice and Evaluation. West Yorkshire, UK: Emerald Publishing Ltd.

Flanagin, A. J., \& Metzger, M. J. (2008). The credibility of volunteered geographic information. GeoJournal, 72(3-4), 137-148.

Guardian, The (2015). What is fossil fuel divestment and why does it matter? Keep in in the Ground. Video. https://www.theguardian.com/environment/video/2015/mar/23/what-fossilfuel-divestment-why-matter-climate-change-video

Hart, P.S. \& Nisbet, E.C. (2011), Boomerang effects in science communication: How motivated reasoning and identity cues amplify opinion polarization about climate change policies. Communication Research, 39(6), 701-723.

Hess, D. (2009). Controversy in the classroom: The democratic power of discussion. New York, NY: Routledge.

Hess, D. E., \& McAvoy, P, (2014), The political classroom: Evidence and ethics in democratic education, New York, NY: Routledge.

Jamieson, K. H. (2008). Echo chamber: Rush Limbaugh and the conservative media establishment. Oxford: Oxford University Press.

Kahne, J., \& Bowyer, B. (2017). Educating for democracy in a partisan age: Confronting the challenges of motivated reasoning and misinformation. American Educational Research Journal, 54(1), 3-34.

Kavanagh, J., \& Rich, M. D. (2018). Truth Decay: An Initial Exploration of the Diminishing Role of Facts and Analysis in American Public Life. Rand Corporation.

Korten, D. C. (2007). The great turning: From empire to earth community. Oakland, CA: Berrett-Koehler Publishers. 
Kull, S., Ramsay, C., \& Lewis, E, (2003), Misperceptions, the media, and the Iraq war. Political Science Quarterly, 118(4), 569-598.

Lankshear, C., \& Knobel, M. (2003). New literacies: Changing knowledge and classroom learning. New York: Open University Press.

Lavine, H. G., Johnston, C. D., \& Steenbergen, M. R. (2012), The ambivalent partisan: How critical loyalty promotes democracy. Oxford, UK: Oxford University Press.

Leiserowitz, A., Maibach, E., Roser-Renouf, C., \& Smith, N. (2010). Climate change in the American mind: Americans' global warming beliefs and attitudes in January 2010. Yale and George Mason University. Yale Project on Climate Change.

Leiserowitz, A., Smith, N. \& Marlon, J.R. (2011). American teens' knowledge of climate change. Yale Project on Climate Change Communication. New Haven, CT: Yale University.

Leiserowitz, A., Maibach, E., Roser-Renouf, C., Feinberg, G., \& Rosenthal, S (2016), Climate change in the American mind: Americans' global warming beliefs and attitudes in March, 2016. Yale Project on Climate Change Communication. New Haven, CT: Yale University and George Mason University Retrieved from: http://environment.yale.edu/climate/publications/

Lester, J. N., \& Paulus, T. M. (2011). Accountability and public displays of knowing in an undergraduate computer-mediated communication context. Discourse Studies, 13(6), 671-686.

Leu, D.J., Kinzer, C.K., Coiro, J., \& Cammack, D. (2004). Towards a theory of new literacies emerging from the Internet and other ICT. In R.B. Ruddell \& N.Unrau (Eds.), Theoretical models and processes of reading (5th ed., pp. 1570-1613). Newark, DE: International Reading Association.

Liu, Z. (2005). Reading behavior in the digital environment: Changes in reading behavior over the past ten years. Journal of Documentation, 61(6), 700-712.

Lombardi, D. \& Sinatra, G.M. (2012). College students' perceptions about the plausibility of human-induced climate change. Research in Science Education, 42(2), 201-217.

Manjoo, F. (2008). True enough: Learning to live in a post-fact society. Hoboken, NJ: John Wiley \& Sons.

Masyada, S., \& Washington, E.Y. (2016). Civil Liberties, media literacy, and civic education in the post-9/11 era: Helping students think conceptually in order to act civically. In W. Journell (Ed.), Reassessing the Social Studies Curriculum: Promoting Critical Civic Engagement in a Politically Polarized, Post-9/11 World, 83-94. Lanham, MD: Rowman \& Littlefield.

McCright, A.M. and Dunlap, R.E. (2011). Cool dudes: The denial of climate change among conservative white males in the United States. Global Environmental Change, 21(4), 1163-1172.

McGrew, S., Ortega, T., Breakstone, J., \& Wineburg, S. (2017). The challenge that's bigger than fake news: Teaching students to engage in civic online reasoning. American Educator, 41(3), 4.

National Association for Media Literacy Education. (2007, November). Core 
principles of media literacy education in the United States. Retrieved (January 7, 2017), from https://namle.net/publications/core-principles.

Oreskes, N. and Conway, E.M. (2010), Merchants of doubt. New York: Bloomsbury Press.

Parker, W. C. (2006). Public discourses in schools: Purposes, problems, possibilities. Educational Researcher, 35(8), 11-18. doi:10.2307/4124788

Prior, M. (2013). Media and political polarization. Annual Review of Political Science,(16), 101-127. doi:10.1146/annurev-polisci-100711-135242

Richardson, L. (2002). Writing sociology. Cultural Studies? Critical Methodologies, 2(3), 414-422.

Sadler, T. D., Chambers, F. W., \& Zeidler, D. L. (2004). Student conceptualizations of the nature of science in response to a socioscientific issue. International Journal of Science Education, 26(4), 387-409.

Stibbe, A. (2015). Ecolinguistics: language, ecology and the stories we live by. London, UK: Routledge.

Taber, C. S., \& Lodge, M, (2006). Motivated skepticism in the evaluation of political beliefs. American Journal of Political Science, 50(3), 755-769.

Tutu, D. (2010). Foreword: The fatal complacency. In F. Kagawa \& D. Selby (Eds.), Education and climate change: Living and learning in interesting times

(pp. xv-xvi). New York: Routledge/Taylor \& Francis.

van der Linden, S. L., Leiserowitz, A. A., Feinberg, G. D., \& Maibach, E. W. (2015). The scientific consensus on climate change as a gateway belief: Experimental evidence. PloS one, 10(2), e0118489.

Vosoughi, S., Roy, D., \& Aral, S. (2018). The spread of true and false news online. Science, 359(6380), 1146-1151.

Washington, H., \& Cook, J. (2011). Climate change denial: Heads in the sand. London: Earthscan.

Wineburg, S., McGrew, S., Breakstone, J. and Ortega, T. (2016). Evaluating Information: The Cornerstone of Civic Online Reasoning. Stanford Digital Repository. Available at: http://purl.stanford.edu/fv751yt5934

\footnotetext{
1 Some examples include the "rural climate dialogues" led by the Jefferson Center and Sierra Club: https://www.youtube.com/watch?time continue=9\&v=ST7-iEVPI1Y or https://www.sierraclub.org/sierra/2018-1-january-february/feature/talking-aboutclimate-change-tr ump-country as well as work by Yale Climate Connections, such as: https:/www.yaleclimateconnections.org/2017/11/changing-ones-views-on-climatechange-throug h-dialogue/
} 